\title{
O CONTATO NO PROCESSO DE CRIAÇÃO DO ATOR: CONSIDERAÇÕES A PARTIR DE RELAÇÕES ENTRE STANISLAVSKI, GROTOWSKI E BOAL E O CONTATO IMPROVISAÇÃO
}

\author{
Marcia Berselli \\ Doutoranda no Programa de Pós-graduação em Artes Cênicas da Universidade Federal do Rio Grande do Sul \\ contato@teatroflexivel.com.br \\ Marta Isaacsson \\ Prof. Titular da Universidade Federal do Rio Grande do Sul \\ Programa de Pós-Graduação em Artes Cênicas da Universidade Federal do Rio Grande do Sul \\ missilva@portoweb.com.br
}

O presente artigo traça um estudo interdisciplinar entre teatro e dança, tendo por ponto de discussão a questão do contato do ator e do bailarino consigo mesmo, com o espaço e com o parceiro. Inicialmente, identifica a importância do "contato" no jogo cênico do ator no contexto dos estudos de três importantes pesquisadores artistas do teatro: Constantin Stanislavski, Jerzy Grotowski e Augusto Boal. A seguir, apresenta o Contato Improvisação concebido por Steve Paxton e traça um paralelo entre as competências técnicas envolvidas no exercício do contato dentro dessa prática com a exigência de contato no trabalho do ator, apresentada pelos estudiosos do teatro. Desta forma, o estudo afirma o interesse pela prática do Contato Improvisação como meio formativo e também de base de processos de criação teatrais.

Palavras-chave

Contato. Ator. Processo de Criação. Contato Improvisação.
This article provides an interdisciplinary study between theater and dance, taking as the point of discussion the question of contact of the actor and the dancer with himself, with the space and with the partner. Initially, it identifies the importance of "contact" in the scenic game of the actor in the context of the studies of three important researcher artists of theater: Constantin Stanislavski, Jerzy Grotowski and Augusto Boal. Then, it presents the Contact Improvisation created by Steve Paxton and draws a parallel between the technical skills involved in the exercise of contact within this practice with the contact required in the actor's work, presented by the theater researchers. Thus, the study affirms the interest in the practice of Contact Improvisation as a formative means and also as base for theatrical creative processes.

Keywords

Contact. Actor. Creative Process. Contact Improvisation. 
Tratar do processo de criação do ator implica um olhar refinado sobre os elementos que compõem o desenvolvimento do acontecimento cênico: atores, espaço, objetos. Há um jogo específico que nasce da forte relação estabelecida entre esses elementos. É neste sentido que caminha nossa exploração: uma investigação sobre o contato enquanto elemento primordial da criação do ator.

O presente estudo, em uma abordagem interdisciplinar que aproxima teatro e dança, busca explorar a importância do contato no processo criativo do ator. Em aproximações a abordagens de Stanislavski, Grotowski e Augusto Boal, reconhecemos a premissa do contato. A partir da identificação da exigência do contato nas abordagens dos três pesquisadores artistas do teatro, encontramos na prática de dança Contato Improvisação, desenvolvida por Steve Paxton e demais colaboradores, um meio de estabelecimento e desenvolvimento do contato do ator consigo mesmo, com os parceiros e com o espaço.

Cotejando as competências técnicas envolvidas na prática do Contato Improvisação com a premissa do estabelecimento do contato no processo criativo do ator, refletimos sobre a utilização da prática de dança no trabalho do ator. Apresentamos o contato enquanto competência primordial do ator, e buscamos evidenciar a possibilidade de seu desenvolvimento a partir da prática do Contato Improvisação. Para tanto, em nosso estudo investigamos os escritos de Stanislavski, Grotowski e Augusto Boal, detalhando suas impressões e apontamentos a respeito da importância do contato na prática do ator, para posteriormente encontrar no Contato Improvisação modos de estabelecimento do contato entre atores, bem como destes com parceiros e com o espaço.
Vivência do contato

no jogo do ator a partir dos estudos de Stanislavski, Grotowski e Boal

A ideia de contato, dentro do sentido aqui adotado, pode ser reconhecida nos estudos de Stanislavski, embora identificado com outra nomenclatura ou mesmo associado a diferentes competências requisitadas ao ator. Ao aprofundar seus estudos, encontramos uma base sólida para nossa definição de contato em seu capítulo intitulado "Comunhão" (Stanislavski, 2013). Comunhão, intercâmbio, linha de comunicação, ligação, adaptação e ajustamentos são noções utilizadas por Stanislavski para definir este contato entre os atores, público e mesmo do ator com os objetos.

Como é diferente quando, ao entrarem em cena esses mesmo atores, um deles quer compartilhar seus sentimentos com o outro, ou convencê-lo de alguma coisa em que acredita, enquanto esse envia todos os esforços para captar sentimentos e pensamentos. Quando o espectador presencia uma dessas trocas emocionais e intelectuais, é como se testemunhasse uma conversa. Participa em silêncio da troca de sentimentos e se deixa emocionar com as experiências dos dois. Mas só enquanto esse intercâmbio prossegue entre os atores é que os espectadores no teatro podem compreender e indiretamente participar do que se passa em cena. Se os atores de fato querem prender a atenção de uma grande platéia, devem fazer todo o esforço possível para manter, uns com os outros, uma incessante troca de sentimentos, pensamentos e ações (Stanislavski, 2013, p. 239).

Há outros momentos em que o contato encontra-se subentendido no princípio técnico da concentração, associado ao ponto de atenção - círculo de atenção - área de atenção e objeto de atenção (Stanislavski, 2013, 
p. 116). Trata-se do contato estabelecido por meio do objeto de atenção do ator, ou seja, ao colocar efetivamente a atenção em determinado objeto, o ator se coloca em contato com este objeto - ou se coloca em busca de contato. Aqui, é importante ressaltar a questão dos objetivos, ponto fundamental para Stanislavski. O objetivo definido auxilia o ator a dirigir sua atenção a algo específico e desta forma estar em contato.

O círculo de atenção pode, assim, ser entendido como uma tentativa de delimitar com o que o ator deseja, ou necessita, estar em contato. Ao definir ou delimitar sua área de atenção por meio do círculo de atenção, define em que locais, e dirigida a quê, vai estar sua atenção, com o que estará em contato. Nesse momento, o contato pode ser do ator em relação ao seu corpo; pode ser dirigido pelo ator a algum objeto próximo ou estar em expansão para algum objeto que esteja a maior distância; pode ser entre o ator e seu colega de cena; ou ainda buscando o público, sendo expandido pelo espaço teatral.

$\mathrm{Na}$ pesquisa de Stanislavski também encontramos nas correntes invisíveis e os raios uma forma de contato. Ao emitir e/ou receber estes raios, o ator está em contato com o outro, há um contato efetivo, uma troca com algo exterior. A palavra troca também aparece nos estudos do mestre russo. Contato é troca, troca entre atores, entre atores e espectadores, entre atores e o espaço, objetos, etc. A troca e os raios estão relacionados à ação-reação. Ao emitir raios ocorre uma troca, pois há ação-reação: as correntes invisíveis partem do ator para o exterior, mas também chegam ao ator em uma constante interação, estando em contato.

Estar em contato efetivo difere de estar em uma relação superficial. Podemos estar numa mesma sala e não estarmos em contato. Podemos nos olhar e isso não significa que há contato. O contato efetivamente se estabelece quando ambos nos colocamos em estado disponível para trocar com o outro, para realizar uma comunhão com o outro. Há aqui uma especificidade muito importante: ao estar em contato efetivo não há espaço para o fazer de conta, trata-se de um estado que depende da entrega e disponibilidade dos dois indivíduos que têm necessariamente de agir - reagir - no momento presente, tomando decisões, fazendo escolhas, colocando-se em estado de risco.

A questão do contato com os objetos, imaginários ou não, é colocada como muito importante nos escritos do mestre russo.

Se tivessem de fazer uma análise, vocês dividiriam seus resultados em percentagem, dando tanto ao ator pelo contato com o seu comparsa, tanto pelo contato com o público, tanto por ter demonstrado o traçado de seu papel, tanto por ter-se ele próprio exibido. A relação entre estas percentagens, na soma total, determina o grau de exatidão com que o ator pôde efetuar o processo de comunhão. Alguns obterão maior cotação nas relações com os comparsas; outros, na sua capacidade de comunhão com um objeto imaginário ou com eles próprios. Estes são os que se aproximam do ideal (Stanislavski, 2013, p. 250).

Ao reconhecer a importância dada por Stanislavski ao contato, é possível compreender que ao se colocar em contato com um objeto o ator está disponível à reação, mas as ações partem efetivamente deste ator. Um objeto é apenas um objeto, não há um impulso de vida nele que não parta do sujeito ator. O objeto não se modifica, mas o ator se modifica e modifi- 
ca o objeto, ao criar este contato. Acreditando que a "realidade é criada pelo observador. $O$ ato de observar alguma coisa muda essa coisa" (Bogart, 2011, p. 127), no caso do objeto, a mudança se relaciona ao movimento do observador. Quando o contato é estabelecido entre dois indivíduos há uma transformação, tem-se agora uma situação de ajustamentos constantes, que partem de ambos os lados.

O direcionamento da atenção do ator ganha também grande importância no trabalho de Grotowski. Assim, o contato é colocado como fundamental no trabalho do mestre polonês, principalmente na fase Teatro dos Espetáculos, que compreende o período de 1959 a 1969, e a partir da qual advém grande parte das referências aqui utilizadas ${ }^{1}$. Sobre determinado exercício, Grotowski diz que "deve ser feito com uma certa força imaginária. Deve-se imaginar que se está em contato constante com alguém, a fim de dar ao exercício uma direção definida" (Grotowski, 1987c, p. 159). A noção de companheiro imaginário também era uma maneira utilizada por Grotowski para que os atores direcionassem seus impulsos e reações ao exterior, com um ponto de atenção específico e delimitado. "Este companheiro imaginário deve ser fixado no espaço desta sala real. Se não se fixar o companheiro num lugar exato, as reações permanecerão dentro da gente". (Grotowski, 1987b, p. 187)

Dessa forma, percebe-se já a importância,

1 Nesta pesquisa não nos deteremos especificamente em cada fase do trabalho de Grotowski, justamente pelo interesse estar no contato, entendido como elemento fundamental que atravessa a trajetória de Grotowski. À parte isso, parece importante salientar que há uma especificidade de cada fase, assim o trabalho sobre o contato pode ser elaborado de modo diferente em cada etapa, de acordo com os preceitos e características de cada momento da pesquisa que, como em Stanislavski, pelo caráter de pesquisa contínua, merece ser analisada em relação ao seu todo, reconhecendo sempre as relações entre cada etapa. em Grotowski - assim como anteriormente apresentado a respeito de Stanislavski - do contato e sua relação com o exterior, no espaço delimitado da sala, com a atenção voltada a um ponto concreto. Nesta questão da atenção ao exterior, pode-se perceber a importância da reação do ator ao exterior. Há um contato do ator com ele mesmo, mas, em direção ao exterior, projetado ao exterior. Um dos exercícios utilizados por Grotowski, ao trabalhar a voz do ator, tinha como proposta que o texto fosse direcionado a um ponto específico do espaço - chão, teto, parede - e assim o ator não ouviria a si mesmo, mas ao eco provocado no encontro da voz com o espaço. "Nesse caso, a nossa atitude, a nossa atenção não está orientada em direção a nós mesmos, mas em direção ao exterior. Porque escutaremos o eco" (Grotowski, 2010a, p. 155). O ator delimita seu ponto de atenção, e reage a partir deste contato com o exterior.

A noção de disponibilidade e comunhão também pode ser aproximada à noção de contato a partir de Grotowski. Para Grotowski, há uma importância muito grande no contato entre os atores na busca de retirar determinadas camadas que encobririam o ser do ator. O contato assim seria uma possibilidade de abertura, de desnudamento, de disponibilidade a partir do qual emergiria o impulso de criação, por meio de uma relação profunda entre os atores.

Jerzy Grotowski, em diversos momentos, seja tratando de exercícios propostos a seus atores, seja falando da própria relação entre os atores, ator e objetos, ator e espaço, aponta para a importância do elemento do contato em seu trabalho. Segundo Grotowski, o

[...] contato é uma das coisas mais essenciais. Muitas vezes, quando um ator fala de contato, ou pensa em con- 
tato, acredita que isto significa olhar fixamente. Mas isto não é contato. Contato não é ficar fixado, mas ver [...] trata-se de contato, e isto me força a modificar meu jeito de agir. (Grotowski, 1987b, p. 187)

Esta modificação na forma de agir, proporcionada ou impulsionada pelo contato, é a reação. O contato leva cada ação a ser reação, pois que efetivamente conectada no momento presente. Grotowski, por meio dos exercícios, buscando eliminar as resistências do ator, buscava chegar a essa reação. "O resultado é a eliminação do lapso de tempo entre impulso interior e reação exterior, de modo que o impulso se torna já uma reação exterior" (Grotowski, 1987a, p. 14).

O contato entre os atores pode ser entendido como um estado de comunhão, no qual a criação aconteceria através de reações. Para além de situações ou personagens, para Grotowski a importância estava nas associações pessoais dos atores, atingidas em contato e com estes reagindo ao exterior - partner, objetos, espaço.

Examinando os estudos de Augusto Boal, em especial aqueles relativos ao início de seu trabalho, fortemente influenciado por suas experiências e estudos teatrais realizados no exterior, e sua aproximação aos escritos de Stanislavski, também encontramos referência ao contato. Os estudos de Stanislavski serão base para suas criações, principalmente a partir do termo inter-relação, utilizado pelo mestre russo e sobre o qual Boal funda suas experimentações junto aos atores do Arena, desenvolvendo procedimentos para a criação a partir da improvisação. ${ }^{2}$

2 "Em 1956, o Arena [Teatro de Arena de São Paulo] iniciou sua fase 'realista'. [...] Fundou-se no Arena o Laboratório de Interpretação. Stanislavski foi estudado em cada palavra e
Sempre em busca da inter-relação, acreditado ser esta a fonte de verdade da cena, Boal enfatizará em suas propostas que os atores mantenham o olho no olho, conduzindo a improvisação a partir dessa premissa fundamental.

Para mim, sempre foi esse o alicerce de todo espetáculo: dois atores se olhando. O olho é a parte mais vulnerável do corpo-humano! Por isso procuramos, recatados, esconder nossos olhos em momentos de emoção. Ou oferecê-los, em momentos de amor. Os atores devem-se oferecer seus olhares. É no olhar que se cria a estrutura do espetáculo. É no olhar que nascem os personagens. É no olhar que se descobre a verdade. Não basta o olho aberto: falo do olhar profundo do qual até os cegos são capazes. (Boal, 2000, p. 142)

Um olhar profundo que desestabiliza, que conecta ao outro. Assim, na fala de Boal, pode-se também perceber a questão do contato na troca do olho no olho que era proposta aos atores. Na sequência do excerto apresentado, Boal apresenta a importância da inter-relação, termo bastante utilizado pelo pesquisador.

Teatro pra mim sempre foi essa energia que passa de um a outro, entre os dois. Como o amor, que não está contido em um ou outro amante, mas existe intenso entre um e outro, também assim a teatralidade não pertence a este ou àquele. Como o raio, é faísca que salta entre dois pólos. (Boal, 2000, p. 143)

praticado desde as nove da manhã até a hora de entrar em cena" (Boal, 1980, p. 176-7). Cabe ressaltar que em 1953, movido pelo desejo de estudar com John Gassner, Boal inicia seus estudos na Columbia University. É Gassner quem auxilia Boal a ser admitido como ouvinte em sessões do Actor's Studio. "Nos Estados Unidos, o famoso Actor's Studio, onde estudarão os melhores intérpretes americanos, é um centro de autoformação fortemente impregnado, em sua origem, pelas teses e orientações metodológicas da escola stanislavskiana" (Roubine, 2003, p. 116). Boal retorna ao Brasil em 1955, e em 1956 é convidado a ocupar a função de diretor no Teatro de Arena, onde permanece até 1971. 
Para Boal, que afirmava ter em Stanislavski sua referência maior (Boal, 2000, p. 141; 143), o centro e base fundamental do teatro é a forte relação entre os participantes. Independente dos recursos e elementos disponíveis à criação, a cena, para ser "viva", dependia dessa relação. Mesmo antes de desenvolver propostas que tinham seus rumos direcionados a partir da intervenção - ou participação direta - do público, e que utilizavam geralmente poucos recursos materiais, como o Teatro-Fórum ou Teatro Invisível, no início da carreira como diretor Boal já percebia a importância da comunhão entre os atores.

Acredito que, mesmo que se disponha de meios materiais, o começo, o âmago - e pensem todos os sinônimos que quiserem para significar a Verdade! - a verdade de todo o teatro é a inter-relação entre seres humanos. É a paixão que entre eles flameja. Aqui está a essência do teatro que pode, depois, vestir-se de ouropéis! Não antes (Boal, 2000, p. 140).

A inter-relação parece ser o termo utilizado por Boal que corresponde, neste estudo, ao que consideramos ser o contato. Relacionada, nos estudos do brasileiro, à "vida" e à "verdade" da cena - noções próximas das utilizadas também por Stanislavski e que mobilizaram sua pesquisa teatral - a inter-relação é termo chave ao se referir ao processo de criação. "Uma cena não é a justaposição de dois atores, mas sim a sua INTER-RELAÇÃO. Não é o que cada um cria isoladamente, mas em conjunto." (Boal, 1996, p. 75, grifo do autor). Em diversas passagens de seus escritos, encontram-se também referências ao "olho no olho" - os exercícios sistematizados por Boal enfatizam a necessidade do contato através do olhar - como forma de potencializar a inter-relação.
Esta, então, pode ser entendida como uma comunhão entre os atores, uma disponibilidade ao outro, um verdadeiro e íntimo contato entre os parceiros de cena.

No capítulo intitulado "O arsenal do Teatro do Oprimido", Augusto Boal (2012, p. 109) apresenta exercícios e jogos "escolhidos em função dos objetivos do Teatro do Oprimido", mas que, como citado em páginas anteriores pelo próprio Boal (2012, p. 106), faziam parte do método utilizado na criação junto ao Teatro de Arena. Boal elenca jogos organizados em cinco categorias, tendo os sentidos como centro das propostas.

$\mathrm{Na}$ primeira categoria, procuramos diminuir a distância entre sentir e tocar; na segunda, entre escutar e ouvir; na terceira, tentamos desenvolver os vários sentidos ao mesmo tempo; na quarta, tentamos ver tudo aquilo que olhamos. Finalmente, os sentidos têm também uma memória, e nós vamos trabalhar para despertá-la: é a quinta categoria. (Boal, 2012, p. 111)

$\mathrm{Na}$ descrição dos exercícios, encontramse propostas que, na busca da ampliação dos sentidos, apresentam princípios aproximados aos trabalhados nas práticas de Contato Improvisação: caminhadas, massagens, estudos sobre a força da gravidade.

Contato improvisação: origem e princípios técnicos

O Contato Improvisação é uma forma de dança desenvolvida por Steve Paxton junto a outros artistas, na década de setenta nos Estados Unidos. Dentro do contexto pós-modernista da dança, esta proposta vinha questionar diversos paradigmas da dança, como a ideali- 
zação do corpo, de saberes sobre a dança, de local específico para se dançar e mesmo da dança para apreciação, de determinada escola ou coreografia a ser seguida, de esforço e habilidade corporal.

O Contato Improvisação envolve improvisação por meio da interação entre os corpos, realizada através de elementos técnicos como rolamentos, compartilhamento de peso, quedas, sustentação e tomadas de decisão em conjunto. Assim, é possível elencar como princípios básicos para esta forma de dança: seguir os pontos de contato, compartilhar o peso, desorientar-se, relaxar, cair, rolar, perceber o outro e o espaço. Em diversos momentos de explicação da dança - definida por vezes como art-sport - Paxton (1997a, p. 37) enfatiza a questão do contato físico, dos suportes corporais e da atenção às leis físicas relativas às suas massas - gravidade, momentum, inércia e fricção.

Estas leis físicas são utilizadas na exploração da relação entre o duo - ou trio, quarteto e/ ou demais possibilidades - que dança Contato Improvisação. Em busca de uma definição do contato na dança, colocaremos brevemente nossa atenção sobre estes conceitos da física (Newton, 1990; Física, 2006), pretendendo relacioná-los a momentos vivenciados na prática do Contato Improvisação.

Dentre as quatro forças fundamentais da natureza, a força gravitacional é aquela cuja manifestação é perceptível do ponto de vista macroscópico, é essa força de atração que mantém os corpos celestes em movimento, bem como a Terra em rotação ao sol, e todos nós presos à Terra. Essa força de atração entre a Terra e um corpo é o que confere peso a este último. Pode-se assim, empiricamente, pensar a sensação de peso, de sustentação, como consequências da gravidade. Pensando a prática do Contato Improvisação, o se deixar cair e o se erguer ou o saltar são movimentos em que a gravidade pode ser percebida, pode-se colocar a atenção sobre ela. O próprio ato de permanecer em pé também é uma manifestação da gravidade, uma manifestação da resistência do corpo em negociação com a gravidade.

A grandeza física que torna possível estudar a transferência de movimento entre dois corpos é a quantidade de movimento linear, também chamada momentum linear. A quantidade de movimento pode ser definida pelo produto da massa $X$ velocidade. Na dança, temos um corpo transferindo seu movimento ao outro. Há um movimento contínuo de dois corpos pelo espaço, no qual um parceiro age sobre o outro e este reage ao primeiro. Pode-se entender como o momentum de um corpo é conservado a partir da Terceira Lei de Newton, a Lei da Ação e Reação.

Já a primeira Lei de Newton apresenta o Princípio da Inércia: um corpo em repouso tende a permanecer em repouso, e um corpo em movimento tende a permanecer em movimento retilíneo e uniforme, considerando a ausência de uma força resultante. Na dança, este princípio pode ser evidenciado no momento do duo em que um parceiro influencia o movimento do outro, ambos em relação ao espaço. Se um dos parceiros aplicar uma força maior sobre o outro, irá alterar o estado de inércia dos corpos, que será recuperado quando a resultante da força aplicada em relação à força de atrito for nula. Quando dois corpos entram em choque com tendência ao movimento, o ponto de contato físico na dança, há a atuação da "força de contato", e um de seus componentes é o atrito - fricção - o componente horizontal, 
que permite o movimento. Já o componente vertical é chamado "força normal", que é uma força de reação ao próprio peso do bailarino em relação ao chão. No contato do bailarino com o chão, a força normal sustenta o peso.

Após essa breve apropriação de conceitos da física, pode-se então definir previamente o contato, no Contato Improvisação, como a relação que se estabelece entre dois ou mais elementos - corpos, objetos, espaço - que compartilham do mesmo espaço sofrendo a ação da gravidade. A partir de uma conjunção de forças externas, buscando o movimento contínuo um corpo (elemento) sofre a influência do outro mantendo um ponto de contato direto.

Segundo Steve Paxton, nas experimentações iniciais da prática estava muito presente a ênfase no físico como realidade, com focos nas sensações físicas, em uma comunicação estabelecida por meio do contato físico, com movimentos rápidos, muitas quedas, e o se jogar sobre o outro. Paxton explicita ao falar da prática de alto impacto que foi apresentada em Magnesium (1971), práticas de

[...] jogar e agarrar que exigiam respostas instantâneas introduzindo-nos a estados de adrenalina. No princípio parecia haver somente duas opções: tratar de seguir o fluxo da comunicação ou resisti-lo. Cada dança é uma série de decisões instantâneas e sucedem a si mesma. A pele sensível está alerta aos pontos de contato. Sinais que indicam aos bailarinos onde estão orientando-os em direção aos seus companheiros e ao chão. Suas percepções se entendem. (Paxton, 1983, $\mathrm{s} / \mathrm{p})$

O Contato Improvisação pressupõe a troca de pontos de contato entre duas ou mais pessoas - ou entre uma pessoa e o espaço. Assim, em uma primeira instância, pode-se en- tender este contato como físico, porém a dança também apresenta momentos de outro tipo de contato, que pode ser chamado de "virtual" utilizando as palavras de Nita Little ${ }^{3}$. Segundo Diego Pizarro, em seus workshops de Contato Improvisação, Little utiliza o termo virtual body.

\begin{abstract}
Para além dos limites da pele, o contato se dá por meio deste corpo virtual que, em intenção e atenção, preenche os espaços entre os corpos e articula qualidades e estados de presença. Por exemplo, ao friccionar uma mão contra a outra e em seguida afastá-las, é possível observar certa atração, magnetismo, calor ou energia entre elas. Independente do nome que se dê para tal fenômeno, a sensação descrita é viva e concreta. (Pizarro, 2011, p. 38)
\end{abstract}

Assim, o contato pode acontecer entre os corpos que se tocam fisicamente, ou entre "energias" que emanam desses corpos como, por exemplo, no exercício "Toque de nuvem" proposto por Little ${ }^{4}$, quando o duo não se toca fisicamente, mas a dança acontece nesse "quase" toque, no momento anterior ao toque, com os corpos completamente concentrados na dança e no "corpo virtual". Em outro exercício, um parceiro está atrás do outro e toca virtualmente apontando o dedo - não o toca fisicamente - e o segundo reage exatamente a este toque, sem ver em que local este toque acontece, nem sentir na "pele", mas sim utilizando todos os sentidos em conjunto. Há uma questão cinestésica que envolve toque, espaço e tempo que é amplamente acionada na dança.

\footnotetext{
3 Bailarina, performer e professora, Nita Little foi uma das artistas que esteve bastante envolvida na criação e desenvolvimento do Contato Improvisação junto a Steve Paxton.

4 Exercício realizado por Marcia Berselli durante o curso "Corpos que falam: explorando a poética da conversa na nossa dança", ministrado por Nita Little, durante o IV Encontro Internacional de Contato Improvisação de São Paulo.
} 
O contato, assim, adquire não só sua forma carnal, mas também uma forma mais sutil evidenciada na relação entre os parceiros. Definimos então duas categorias de contato, que auxiliarão o desenvolvimento da presente reflexão: o contato real e o contato virtual.

O contato é aqui tratado como uma relação entre um corpo e um elemento que é exterior a esse corpo, com um ponto específico de contato - físico ou virtual - a uni-los resultando em transformações.

Ao tratar do contato, lidamos com mecanismos de contato e com elementos de contato. Por mecanismos de contato entendemos os meios, canais, pelos quais se entra em contato com o outro. Trataremos assim, a partir das definições anteriores, os mecanismos de contato em duas esferas: real e virtual. $\mathrm{Na}$ esfera do real, apresentam-se os seguintes mecanismos: toque, olhar, escuta; já o contato virtual é entendido como aquele em que não há um contato explícito, mas sim o contato por meio de trocas de energias. Na questão dos elementos de contato, trata-se do objeto de contato, ou seja, com quem ou o quê se entra em contato: pessoas, objetos, espaços.

\section{Cruzamentos entre o} contato improvisação e o teatro: princípios e procedimentos envolvendo o contato

O Contato Improvisação, ao propor a interação de dois corpos no espaço, traz a experiência de contato, não apenas físico em sua dimensão carnal, mas também sinestésico em sua maior amplidão (olhar, escuta, atenção, irradiação). Segundo Paxton, o
[...] foco principal do treinamento é reafirmar os sentidos. Todos os sentidos devem tornar-se elásticos o suficiente para navegar através do espaço esférico, e poder afrontar qualquer posição, qualquer troca de aceleração e/ ou velocidade. (Paxton, 1983, s/p.)

Percebe-se, assim, a necessidade de uma percepção dos sentidos ampliada. Esta é uma constatação importante, já que esta abertura e disponibilidade têm a ver com as decisões e escolhas realizadas no momento presente, em contato com os parceiros e com o espaço. Stanislavski, ao tratar da comunicação - que pode ser entendida como uma das nomenclaturas utilizadas pelo mestre russo, correspondente à noção de contato em nossa pesquisa - expõe que

[...] nós nos servimos de todos os nossos cinco sentidos e de todos os elementos de nossa conformação interior e exterior para nos comunicarmos. Emitimos raios e os recebemos, usamos os olhos, a expressão fisionômica, a voz e a entonação, as mãos, os dedos, nosso corpo todo, e em cada caso fazemos os ajustamentos correspondentes que se tornarem necessários, quaisquer que eles sejam. (Stanislavski, 2013, p. 270)

Assim, observa-se que no processo de criação há uma exigência de inteireza do ser do ator, e que pode ser alcançada através de exercícios que atualizam os princípios do Contato Improvisação. Nesta dança, o movimento só acontece na relação entre os dois corpos, relação na qual não temos um comandante e um comandado, mas sim duas forças em homogeneidade, na qual há constantes ajustamentos, em um momento alguém pode propor mais, no outro o parceiro pode se tornar propositor e, geralmente, a perspectiva da dança é esse diálogo: propostas que partem dos dois lados 
em um comum acordo não verbal. Esse acordo não significa que em todos os momentos há uma concordância, podendo haver momentos da dança em que um parceiro não aceite o movimento, mas esta colocação não é vista como uma negação, e sim como uma nova proposição modificando o que estava instaurado.

Sem uma linha de movimentos definida, a dança se faz dessa constante interação de movimentos, onde não há a preponderância de um praticante sobre o outro. Ao olhar um duo dançando Contato Improvisação, provavelmente não será possível definir de onde parte o movimento, quem está propondo e quem está aceitando, já que a dança se faz no "entre", nas contínuas reações de ambos os dançarinos. A noção de reação poderá servir em auxílio do que entendemos por contato: a relação que se dá entre dois atores e que pressupõe uma troca, um diálogo, uma sucessão de reações, que possibilitam a emergência deste "entre" que contém em si (ou é) a possibilidade do impulso criativo. Segundo Grotowski, "na relação viva com os outros se recebe um estímulo e se dá uma resposta. São justamente esses os impulsos: do pegar e responder; dar ou, se quiserem, reagir". (Grotowski, 2010b, p. 132) Pegar e responder, ou reagir, são noções que podem servir de impulso à reflexão sobre as decisões imediatas exigidas na prática do Contato Improvisação.

$\mathrm{Na}$ improvisação de movimentos, na qual se recebe um estímulo e se responde a ele, desenvolve-se a capacidade da reação, ação que brota de um impulso interno em direção ao exterior. Há um saber que se desenvolve no praticar, um repertório relacionado à prática que é incorporado pelos praticantes. Este saber proporciona que se estabeleça um diálogo cinestésico fluido entre os parceiros nas toma- das de decisão em tempo real. Para Andrew Hardwood, o Contato Improvisação envolve tomar decisões no momento presente, "decisões imediatas".

Contato Improvisação é isso: a capacidade da consciência de pegar todas as informações dentro e ao redor de $\mathrm{si}$, que as outras pessoas estão emitindo. Quando você está improvisando com outras pessoas, muitas coisas vão acontecendo. Você está tentando pegar todas as informações e filtrar na sua mente, na imaginação, no sentido, pela sua história [...] quem você é como pessoa, o que gosta e o que não gosta, com o que se preocupa e com o que não se preocupa. Tomar a meIhor decisão que você pode conceber como sendo possível naquele momento, e é muito relativo, é totalmente relativo. [...] talvez porque eu tenha muita experiência, minhas decisões, mesmo que instantâneas, já estão baseadas nas experiências prévias. (Hardwood; Zacharias, 2012, p. 165)

Essas decisões imediatas podem ser entendidas como as reações requeridas por Grotowski. As decisões, mesmo sem serem préconcebidas, estão relacionadas ao passado e ao futuro do ator, ao que este vivenciou e ao que pretende vivenciar, sua projeções. $\mathrm{E}$ a dificuldade, então, é não ficar estagnado nesse passado ou futuro, mas sim encontrar a disponibilidade para, em relação a estes tempos, tomar a melhor decisão no momento presente: a reação.

Para tanto, é necessário que o corpo esteja disponível a reagir imediatamente. Ou seja, preparado para agir, porém sem antecipações ou tensões excessivas. Augusto Boal, em suas proposições acerca da Poética do Oprimido, indicava que o trabalho deveria "começar pelo próprio corpo das pessoas interessadas em participar da experiência”. (Boal, 1980, p. 133) 
Podemos mesmo afirmar que a primeira palavra do vocabulário teatral é o corpo humano. Por isso, para que se possa dominar os meios de produção teatral, deve-se primeiramente conhecer o próprio corpo, para poder depois torná-lo mais expressivo. (Boal, 1980, p.131)

Nessa fase de seu trabalho, quando a abordagem já está relacionada a transformar o espectador em espect-ator, Boal se preocupa em tornar conscientes as estruturas musculares e padrões corporais, que segundo o teatrólogo estão diretamente relacionados aos modos de vida de cada pessoa, às suas profissões, ao status social (Boal, 1980, p. 134). O trabalho de Boal com os atores do Teatro de Arena também iniciava sob a premissa de sensibilizar os corpos muscularmente automatizados e mecanizados.

O ator, como todo ser humano, tem suas sensações, suas ações e reações mecanizadas, e por isso é necessário começar pela sua desmecanização, pelo seu amaciamento, para torná-lo capaz de assumir as mecanizações da personagem que vai interpretar (Boal, 2012, p. 84, grifo do autor).

Para tanto, Boal propunha aos atores exercícios sensoriais, seguindo "em linhas gerais as indicações de Stanislavski” (Boal, 2012, p. 84). Essa primeira fase de trabalho englobava exercícios sensoriais, de memória, de imaginação, de emoção e exercícios musculares. Estes últimos com o objetivo de que o ator pudesse relaxar o corpo e tomar consciência de seus músculos. Stanislavski afirmava que o excesso de tensão era prejudicial à criação, e que seria necessário ao ator desenvolver "uma espécie de controle, como se fosse um observador. Esse observador, em todas as circunstâncias terá de impedir que haja, em qualquer ponto, a menor quantidade extra de contração" (Stanislavski, 2013, p. 134). Desta forma, a disponibilidade corporal - no sentido do controle das tensões - é evidenciada no processo de criação de Boal e Stanislavski. Assim também para Grotowski, para quem o ator deveria encontrar um fluxo entre o que era necessário contrair e o que relaxar.

Não é completamente verdade que o ator só tem que ficar bem relaxado. Muitos atores fazem uma quantidade enorme de exercícios de relaxamento. Mas quando estão no palco, eles têm dois resultados fatais. Um dos resultados é que ficam imediatamente contraídos. Antes de começar, eles relaxam, mas quando se vêem diante de uma dificuldade, se contraem. Para outros, o resultado é que ficam como um lenço, astênicos, psicastênicos no palco. O processo da vida é uma alternância de contrações e descontrações. Então o ponto não é somente contrair e descontrair, mas encontrar esse rio, esse fluxo, no qual o que é necessário está contraído e o que não é necessário está relaxado. (Grotowski apud Richards, 2012, p. 111, grifo do autor)

O Contato Improvisação apresenta como um dos princípios básicos o corpo relaxado em busca de uma disponibilidade corporal. Nesta prática, aspectos técnicos são trabalhados para que as amplas possibilidades corporais possam ser utilizadas conscientemente. Segundo Banes,

[...] um programa técnico mínimo treina para desenvolver os músculos para facilitar o alongamento, centralização, compartilhar o peso e aumentar a ação conjunta. $O$ treinamento também ajuda à consciência de certos princípios: sentido de tempo, orientando-se para o espaço e para o parceiro, descobrindo atitude, ampliando a visão periférica. [...] Grande parte do tempo 
aprendendo o básico é dedicado ao relaxamento e suaves aquecimentos. Quando o corpo está relaxado, surpresas e situações de raciocínio rápido podem ser encontradas com força serena. ${ }^{5}$

O corpo relaxado do Contato Improvisação, citado por Banes, não supõe um corpo em completa inação, mas um corpo capacitado a reagir sem antecipações. Ao suprimir tensões excessivas por meio de exercícios e jogos que propiciam o contato com o outro e com o espaço, desenvolve-se uma abertura e uma disponibilidade ao aqui-e-agora.

Ainda segundo Hardwood, "como em outras improvisações, a pergunta é: o que se passa no presente?" (Hardwood; Zacharias, 2012, p. 162). Ao questionar o momento presente, envolvendo também questões de risco e possibilidades de não êxito, o Contato Improvisação possibilita uma aproximação a este fazer efetivo, que é possibilitado pela força do contato. O contato aqui vai muito além do físico, envolve uma relação entre as pessoas que dançam, uma entrega e um foco muito específico para esse momento atual da dança. Da mesma forma, presente no momento atual da cena, o ator tem a possibilidade de se colocar de forma íntegra na ação.

O contato transforma toda a ação em reação, pois que fundado no estabelecimento de um entre-dois, espaço singular nascido de um encontro específico, e nutrido pelas reações de ambos os lados. Assim, quando Stanisla-

\footnotetext{
5 "A minimal technical program trains one to developed the muscles to facilitate stretching, centering, taking weight, and increasing joint action. The training also aids consciousness of certain principles: sensing time, orienting oneself to space and to one's partner, discovering attitude, expanding peripheral vision. [...] Much of the time spent learning the basics is devoted to relaxation and gentle warm-ups. When the body is relaxed, surprises and emergencies can be met whit calm strength". (Banes, 1987, p. 65)
}

vski diz que no palco o ator deve estar aberto a reagir a tudo o que o cerca, pode-se perceber a necessidade de estar disponível ao contato e a manter este contato com todos os elementos da cena.

No Contato Improvisação, quando se constata que a dança efetivamente aconteceu quando os dançarinos não mais estão preocupados com os movimentos a fazer, mas entram em um fluxo de movimentos em relação - o que se percebe são os dois dançarinos envolvidos de tal maneira em pequenos ajustamentos, buscando sempre manter algum ponto de contato, sendo que o que é visto são reações. Reações ligadas ao entre criado pelo contato, cuja origem pode não ser visível, já que promovidas pelos dois, no entre. José Gil problematiza este momento em que a dança efetivamente acontece:

[...] o que é que faz "pegar" o movimento, quando no início os movimentos de cada corpo não "agarravam" os do outro? [...] Trata-se de facto de descrever as condições de captura recíproca de dois corpos no Cl. Porque os movimentos de um bailarino vão ao mesmo tempo comandar e obedecer aos movimentos do outro bailarino; cada um antecipa e adivinha os movimentos do outro como se fossem os seus próprios movimentos, como se os movimentos do outro se desenrolassem segundo a carta dos seus movimentos actuais. (Gil, 2001, p. 144)

Assim Gil entende o momento da dança em que os corpos efetivamente dialogam, sem que um bailarino comande e um seja comandado, mas quando ambos entram em um estado que entendemos como de contínuas reações. Não há mais um bailarino agindo e o outro reagindo, mas ambos reagem em um continuum de movimentos improvisados, com o objetivo em comum de manter um ponto de contato. 
Acreditamos ser importante destacar a palavra utilizada por Gil, "agarrar", pois ela conduz a um conceito de Stanislavski que sem dúvida aproxima os momentos de criação do ator em cena e no Contato Improvisação. O verbo "agarrar" remete imediatamente a uma imagem bastante física, a uma ação explícita. Stanislavski, ao problematizar a questão de quando uma cena efetivamente acontece, com a "verdade" tão almejada pelo mestre, traz a ideia de "agarrador". O professor da ficção criada por Stanislavski para escrever sobre seu método de criação, Tórtsov, responde da seguinte maneira quando questionado sobre o agarrador:

É aquilo que um buldogue tem nas mandíbulas. Nós atores temos de ter a mesma capacidade de agarrar com os nossos olhos, ouvidos e todos os nossos sentidos. Se um ator tem de ouvir, que o faça atentamente; se deve cheirar, que cheire com força; se tiver de olhar para alguma coisa, use os olhos de fato. (Stanislavski, 2013, p. 259)

Em ambos os casos, trata-se do momento em que a ação ocorre efetivamente, ou seja, é reação. A dança "pega" quando o duo de Contato Improvisação está em um verdadeiro contato no qual ambos reagem continuamente.

Aqui é possível perceber a grande questão do contato, que se coloca neste entre criado. Um entre que diz respeito ao ator e seu ponto de contato: objeto, espaço, o outro. A partir das considerações estabelecidas até então, entendemos o contato como propiciador/ propulsor do impulso criador, já que é o entre criado no contato que promove o impulso, um impulso emocional e físico, que se transforma em reação. O impulso a partir do contato será reação porque há uma troca entre os envolvidos, na qual os dois se modificam, uma troca motivada por uma ação anterior.

Ao trazer o Contato Improvisação, prática que reconhecemos ter origem na dança, ao teatro, buscamos estabelecer uma relação interdisciplinar entre Dança e Teatro, afirmando uma possibilidade, no plano da técnica, de entrelaçamento. Por meio de aprofundamento teórico, buscou-se destacar na prática do Contato Improvisação princípios operatórios que constituem exigências técnicas também do teatro, o que torna essa prática de dança um interessante veículo de formação do ator. Com o presente estudo, afirmamos a prática do Contato Improvisação como meio formativo e também de base de processos de criação teatrais que partam das experiências sensíveis dos atores.

Referências

BANES, Sally. Steve Paxton: Physical Things. In: Terpsichore in Sneakers: Post-Modern Dance. Boston: Houghton Mifflin, 1987, p. 57-70.

BOAL, Augusto. Hamlet e o filho do padeiro: memórias imaginadas. Rio de Janeiro: Record, 2000.

. Jogos para atores e não atores. $15^{\mathrm{a}}$ ed. Rio de Janeiro: Civilização Brasileira, 2012.

- Teatro do Oprimido e Outras Poéticas

Políticas. $4^{\text {a }}$ ed. Rio de Janeiro: Civilização Brasileira, 1980.

. Teatro legislativo: versão beta. Rio de Janeiro: Civilização Brasileira, 1996. 
BOGART, Anne. A preparação do diretor: sete ensaios sobre arte e teatro. [Tradução de Anna Viana]. São Paulo: Editora WMF Martins Fontes, 2011.

Física: Ensino Médio. Vários autores. $2^{\mathrm{a}}$ ed. Curitiba: SEED-PR, 2006.

GIL, José. Movimento total: o corpo e a dança. [Trad. Miguel Serras Pereira]. Lisboa: Relógio D’Água Editores, 2001.

GROTOWSKI, Jerzy. 1987a [1965]. "Em Busca de um Teatro Pobre". In: GROTOWSKI, Jerzy. Em Busca de um Teatro Pobre. Rio de Janeiro: Civilização Brasileira, p. 13-22.

1987b [Jan, 1966]. "O Discurso de Skara”. In: GROTOWSKI, Jerzy. Em Busca de um Teatro Pobre. Rio de Janeiro: Civilização Brasileira, p.186-198.

. 1987c [1966]. "O Treinamento do Ator (1966)*”. In: GROTOWSKI, Jerzy. Em Busca de um Teatro Pobre. Rio de Janeiro: Civilização Brasileira, p. 145-175.

2010a [Maio, 1969]. A voz. In: FLASZEN, L e POLLASTRELLI, C. O Teatro Laboratório de Jerzy Grotowski 1959-1969: Textos e materiais de Jerzy Grotowski e Ludwik Flaszen com um escrito de Eugenio Barba. $2^{\mathrm{a}}$ ed. São Paulo: Perspectiva: Edições SESC SP; Pontedera, IT: Fondazione Pontedera Teatro, p. 137162. 2010b [Out, 1968]. Teatro e Ritual. In: FLASZEN, L e POLLASTRELLI, C. O Teatro Laboratório de Jerzy Grotowski 1959-1969: Textos e materiais de Jerzy Grotowski e Ludwik Flaszen com um escrito de Eugenio Barba. $2^{\mathrm{a}}$ ed. São Paulo: Perspectiva: Edições SESC SP; Pontedera, IT: Fondazione Pontedera Teatro, p. 119-136.

HARDWOOD, Andrew; ZACHARIAS, Paula. Condições climáticas do Contato-improvisação. In: Cena, corpo e dramaturgia: entre tradição e contemporaneidade. Org. Antonia Pereira, Marta Isaacsson e Walter Lima Torres. Rio de Janeiro: Pão e Rosas, 2012.

NEWTON, Isaac. Princípia: princípios matemáticos de filosofia natural. [Tradução de Triste Ricci... [et.al.]]. São Paulo: Ed. Universidade de São Paulo, 1990.

PAXTON, Steve. A definition. 1997a [1978/79] In: Contact Improvisation Source Book: collected writings and graphics from Contact Quaterly dance journal 1975-1992. Massachusetts: Contact Editions, p. 37-38.

. Queda depois de Newton. 1983. Disponível em: http://entrandoemcontato.blogspot. com.br/p/sobre-contato-e-mais.html. Consultado em 27/07/2013.

PIZARRO, Diego. Fazendo contato: a dança Contato-Improvisação na preparação de atores. Mestrado/UnB. Brasília, 2011. 
RICHARDS, Thomas. Trabalhar com Grotowski sobre as ações físicas. Com um prefácio e o ensaio "Da companhia teatral à arte como veículo" de Jerzy Grotowski. [Tradução de Patricia Furtado de Mendonça]. São Paulo: Perspectiva, 2012.

ROUBINE, Jean-Jacques. Introdução às grandes teorias do teatro. [Tradução de André Telles]. Rio de Janeiro: Jorge Zahar Ed., 2003.

STANISLAVSKI, Constantin. A preparação do ator. [Tradução de Pontes de Paula Lima]. 30a ed. Rio de Janeiro: Civilização Brasileira, 2013.

Recebido: $31 / 08 / 2016$

Aprovado: 16/12/2016 